\title{
Trend in the Containerization Development of Tianjin Port Based on Logistic Growth Model
}

\author{
Wang Guanhui \\ 1School of International business, Tianjin Foreign Studies University \\ 2Tianjin International Development Research Institute \\ Tianjin, China \\ e-mail: newhop@126.com
}

\begin{abstract}
This paper offers a simulation of the development track of Tianjin Port from the perspective of the similarities between port development and population model. The simulation shows that, as the midpoint of the growth trajectory is passed, it is forecast that the development of Tianjin Port will gradually slow down. The competitiveness of Tianjin Port is understood in the comparison with other listed port group companies in China. The study shows that the overall competitiveness of Tianjin Port is strong, but it still has space for further development in management efficiency and hinterland transportation network construction.
\end{abstract}

Keywords- Logistic Growth model; Tianjin port; natural network; Containerization; population model.

\section{INTRODUCTION}

The collecting and distributing system of Tianjin Port and its capacity are interdependent. The prerequisite for analyzing whether the collecting and distributing system of Tianjin Port matches its current development pace is to examine its current development speed and prospective advancement. Therefore, the core of this analysis is to examine and forecast the scale of the port.

The criteria for judging the current development of a port is varied, such as annual throughput, annual profit, staff number, and etc ${ }^{[1-7]}$. The analysis can be horizontal or vertical. Zhang Shengxian et $\mathrm{al}^{[8]}$ point out that port collecting and distributing study can be divided into two areas. One is port-centered, focusing on port traffic and freight handling. The other studies the overall collecting and distributing system of port hinterland. Their forecast of port scale is based on optimally weighted combination, but the study does not go further. Basing her study on fluid dynamics and entropy principle, $\mathrm{Li} \mathrm{Yun}^{[9]}$ examines port traffic flow. She identifies and evaluates the parameters for port area, road and yard. Deng Chaofeng ${ }^{[10]}$ forecast the throughput of Tianjin Port, Qingdao Port and Dalian Port, using logistic growth model, exponential smoothing and gray system theory. However, his study fails to point out the relation between collecting and distributing capacity and port scale. Gao Qin and Ma Junhai $^{[11]}$ offer theoretical and quantitative analysis on the co-opetition strategy between container terminals, using modified population model. They highlight the importance of co-operation in competition.

\section{Data Analysis}

Container throughput is internationally accepted as a criterion for assessing port scale. As ports in the world have different management foci and the economic indicators of ports are closely related to the economic development of their hinterlands, the comparison between ports, especially between different international ports, requires indicators that are not affected by objective factors of the ports. And container throughput is one of the few such indicators. Port throughput is one of the important indicators to measure the capacity of modern transportation. The computation of throughput is internationally agreed and unified and the data are easily available. Therefore, throughput is an ideal indicator.

This paper offers a case study of Tianjin Port, and the data are collected from the quarterly, midyear and annual reports of Tianjin Port. Port.

The scatter plot below shows the throughput of Tianjin

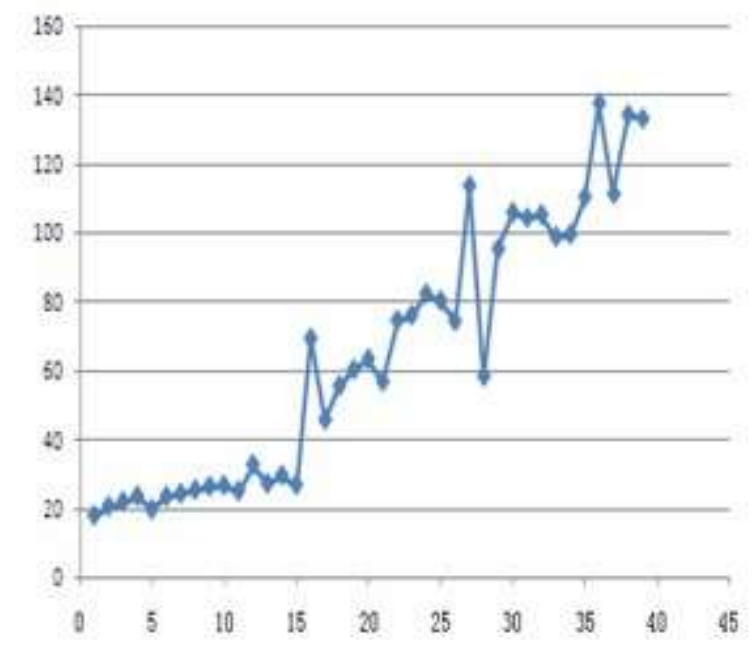

Figure 1. Scatter plot of Tianjin Port Throughput

The plot shows that the quarterly throughput follows a seasonal pattern. Therefore, seasonal modification is made and the method of moving average is used so that the simulation will produce a clearer trend. The scatter plot below is produced after seasonal modification.

Fig .2 shows that the overall growth trajectory of Tianjin Port throughput is J-shaped, which meets the requirement for the application of logistic growth model. 


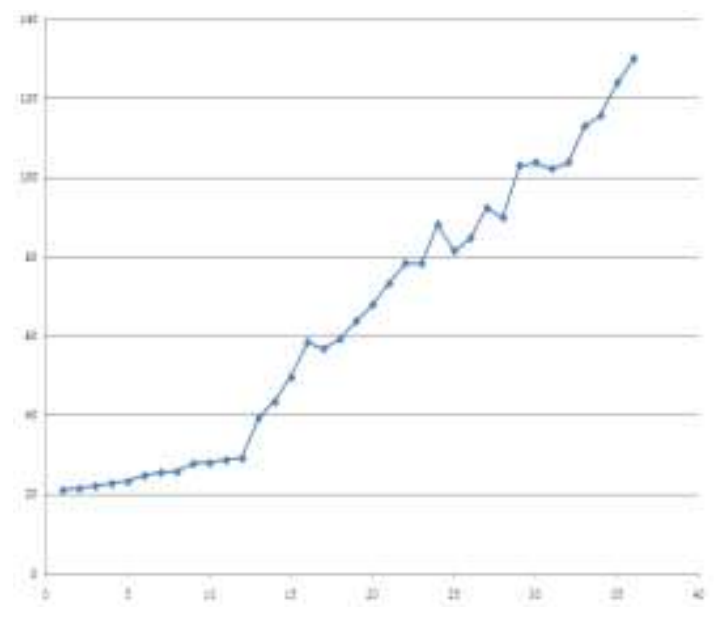

Figure 2. Scatter plot of Tianjin Port Throughput after Seasonal Modification

III. The Similarities Between Port Development and Population Growth

As an organic whole, port development shares many similarities with population growth.

First, their existence conditions are similar. Biological population exists and grows in certain natural and social conditions. Likewise, port development relies on such natural and social conditions like water depth, geographical location, and hinterland economic scale. There is a special relationship between the formation, development and decline of ports and the natural environment. Take inland Yangzhou Port as an example. Yangzhou Port was an ordinary port before the creation of the Beijing-Hangzhou Grande Canale. After the Grande Canale was open to traffic, Yangzhou Port experienced rapid development and grew into a booming port until a century ago. Later, with the decline in the traffic capacity of the Grande Canale and the low growth rate of its hinterland's economy, Yangzhou Port went through a period of growth decline. In recent years, aided by factors such as the economic revival of its hinterland and the improvement of water depth, Yangzhou Port has stepped into the fast lane of its development.

Second, their growth trajectories are similar. The growth trajectory of biological population is S-shaped. So is that of ports, which consists of slow development in starting stage, rapid growth stage, and bottleneck stage. Due to limited external resources, port development has a ceiling. Constrained by factors such as its geography, climate, and market, the growth trajectory of ports is also S-shaped.

Third, they are similar in competitive environment. Biological population lives with rival population. So are ports. Take inland Tianjin Port as an example. As one of the major import and export ports of coal in North China, Tianjin Port is facilitated with coal trade logistics services. However, it is not the only one boasting such conveniences. It faces rivalry from other ports in Bohai Rim such as Qinhuangdao Port, Qingdao Port, and Caofeidian Port.

\section{The Construction of Logistic Growth Model}

As one of the models of population growth, logistic growth model shows the growth curve of a population in a constrained environment. In its initial stage, population growth is slow, and population size is maintained at low levels. With the enlargement of population size, the population growth accelerates. When the population size reaches or approaches the maximum carrying capacity of the restrained environment, the population growth rate slows down to low level till it approaches 0. Overall, logistic growth curve is S-shaped, as shown in Fig .3.

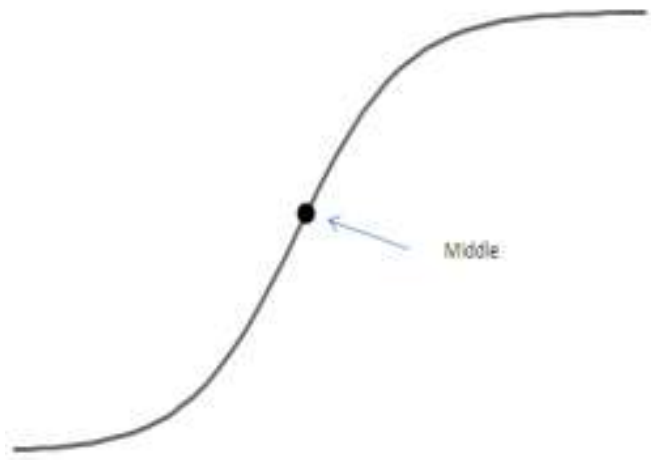

Figure 3. Logistic Growth Curve

The midpoint is of great significance in determining the phase of population growth.

The following logistic growth model is constructed:

$$
\frac{d N}{d t}=r N\left(1-\frac{N}{K}\right)
$$

$\mathrm{N}$ represents population size, $\mathrm{r}$ the natural growth rate of population, and $\mathrm{K}$ the carrying capacity for the environment. Here $\mathrm{K}$ represents the maximum throughout of the port.

As this paper intends to make a range estimation of $\mathrm{k}$, it is therefore necessary to modify the original equation as the following:

$$
\frac{K}{N(K-N)} d N=r d t \rightarrow \ln \frac{N}{K-N}=r t-C
$$

$\rightarrow N=\frac{K}{1+e^{-r t+C}} \rightarrow \frac{1}{N}=\frac{1}{K}+\frac{e^{C} \cdot e^{-r t}}{K}$

Make $Y=1 / N, a=e^{C}, X=e^{-t}$,

among which $a=K / N_{0}-1$.

Assume $N_{0}$ take 1 . Then $a=K-1$

Therefore, $Y=(1-1 / K) X^{r}+1 / K$.

Make $m=1-1 / K$

Then, the fitted equation is expressed as $Y=m X^{r}+1-m$.

The values for $y_{i}, x_{i}$ are obtained from transformation of the value of $N_{i}, t_{i}$. 


\section{Result and Analysis}

The symbiosis model constructed in this study is as follows.

$$
\left\{\begin{array}{l}
\frac{d N_{1}}{d t}=-\frac{r_{1}}{K_{1}} N_{1}^{2}+\frac{\mu r_{1}}{K_{2}} N_{1} N_{2}+\varepsilon r_{1} N_{1} \\
\frac{d N_{2}}{d t}=-\frac{r_{2}}{K_{2}} N_{2}^{2}+\frac{v r_{2}}{K_{2}} N_{1} N_{2}+\eta r_{2} N_{2}
\end{array}\right.
$$

The model shows that the key is to make $\mu>1$. When the throughput and highway mileage both reach equilibrium, then

$$
\begin{aligned}
& d N_{1} / d t=0 d N_{2} / d t=0 \\
& \left\{\begin{array}{l}
\frac{d N_{1}}{d t}=0 \\
\frac{d N_{2}}{d t}=0
\end{array} \Rightarrow\right. \\
& \left\{\begin{array}{l}
K_{1} \\
-\frac{r_{1}}{r_{2}} N_{1}^{2}+\frac{\mu r_{1}}{K_{2}} N_{1} N_{2}+\varepsilon r_{1} N_{1}=0 \\
-\frac{v r_{2}}{K_{2}} N_{1} N_{2}+\eta r_{2} N_{2}=0
\end{array}\right.
\end{aligned}
$$

Solve this set of equations, then four equilibrium points will be obtained.

$$
\begin{aligned}
& E_{1}=(0,0), \\
& E_{2}=\left(0, K_{2} \eta\right), \\
& E_{3}=\left(K_{1} \varepsilon, 0\right), \\
& E_{4}=\left(\frac{\mu \eta+\varepsilon}{1-\mu \nu} K_{1}, \frac{\beta \varepsilon+\eta}{1-\mu \nu} K_{2}\right)
\end{aligned}
$$

In this system, the positive equilibrium of the system should be taken into consideration. As the first three equilibrium points is of little referential significance, the fourth equilibrium point is considered. The condition for the positive equilibrium of the fourth point is as follows.

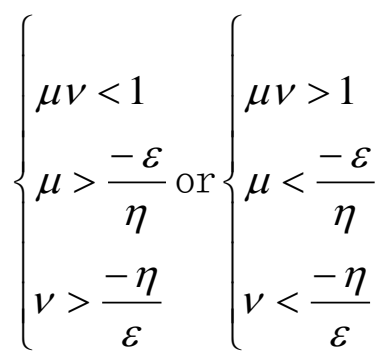

As we made $0<v<1,2<\varepsilon<\eta<\mu+1$ in previous assumption, therefore, the condition for the positive equilibrium of the fourth point is $\mu \nu<1$.
Meanwhile, as the condition of $N_{2}^{*} \geq l N_{1}^{*}$ should be satisfied to be of practical significance, the condition of $l K_{1}(\mu \eta+\varepsilon) /(1-\mu v) \leq K_{2}(v \varepsilon+\eta) /(1-\mu v)$

should also be satisfied, or $(\mu \eta+\varepsilon) l K_{1} \leq(v \varepsilon+\eta) K_{2}$.

This study is based on the statistics of Tianjin Port between 2001 and 2009. Fig. 4-1 shows the development trend of Tianjin Port Throughput and highway mileage in recent years.

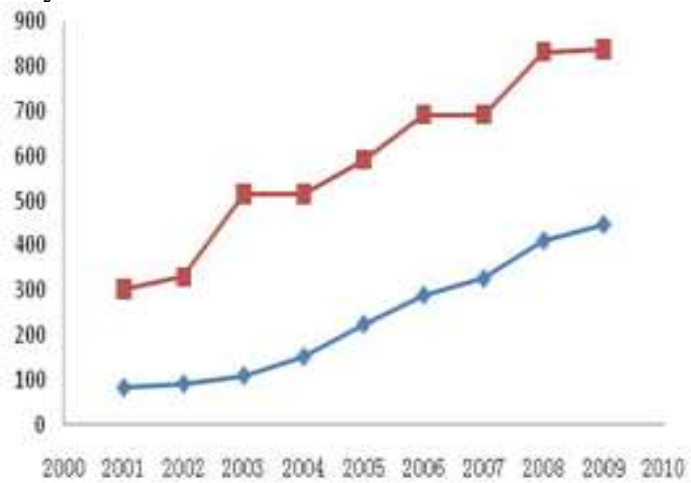

Figure 4. Development trend of Tianjin Port Throughput and Highway Mileage

Fig .4(Diamonds indicate the throughput of Tianjin Port (in 10,000 TEU), and triangles indicate the highway mileage (in 1 kilometer)) shows that the growth trajectories of Tianjin Port throughput and highway mileage follow similar pattern, but it doesn't show any obvious correlation between the two. Therefore, proceeding from the ratio of the two, this paper compares the ratio of the two with the throughput of Tianjin Port so that a relatively clear result will be obtained.

The finding of the analysis is shown in the Fig .5:

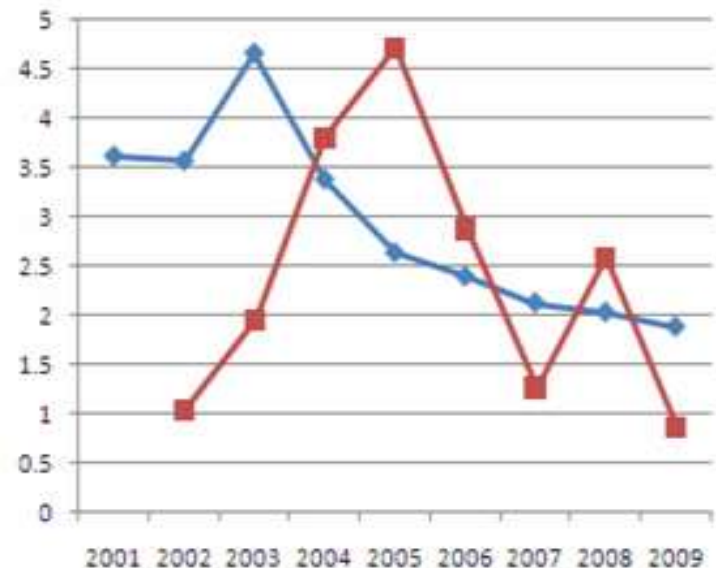

Figure 5. The Ratio of Tianjin Port Throughput and Highway Mileage

Fig .5 (Diamonds indicate the ratio of highway mileage and the throughput of Tianjin Port, and triangles indicate the throughput growth*10) shows that: the first, when the ratio of highway mileage and the throughput is above 3.5, then the throughput growth accelerates; however, when the ratio is below 3.5, then the throughput growth decelerates; the second, there is one peak in the trajectory of the ratio of highway mileage and the throughput, and two in the trajectory of throughput; the later of the two peaks 
obviously is lower; as a result of time lag, after the ratio of highway mileage and the throughput reaches the peak, its influence will be transferred to the growth of throughput after one or two time intervals; the third, the ratio of highway mileage and the throughput has been decreasing since 2005; meanwhile, the growth of throughput has been decelerating, suggesting that the distribution and transportation capacity of Tianjin Port has been constraining the development of Tianjin Port.

As the fitted equation contains exponential term, it is difficult to work out the equation with the commonly used generalized least squares. Therefore, genetic algorithm is used to obtain the fitting item. The range for $\mathrm{m}$ in this study is $0.993-0.9995$, and that for $\mathrm{r}$ is $0-10000$. Euclidean distance is used for the measurement of fitting error.

In order to achieve satisfactory fitting result, the study discarded several initial data with high discrete degree. The fitting result achieved by using Matlab Toolbox is that $\mathrm{m}=0.996, \mathrm{r}=0.24$, and the error is 0.01 , within the range of acceptance. The result also shows that the value of $K$ is 250. Fig .6 shows the fitting result, where the blue curve represents the true value, and the green curve the fitted value.

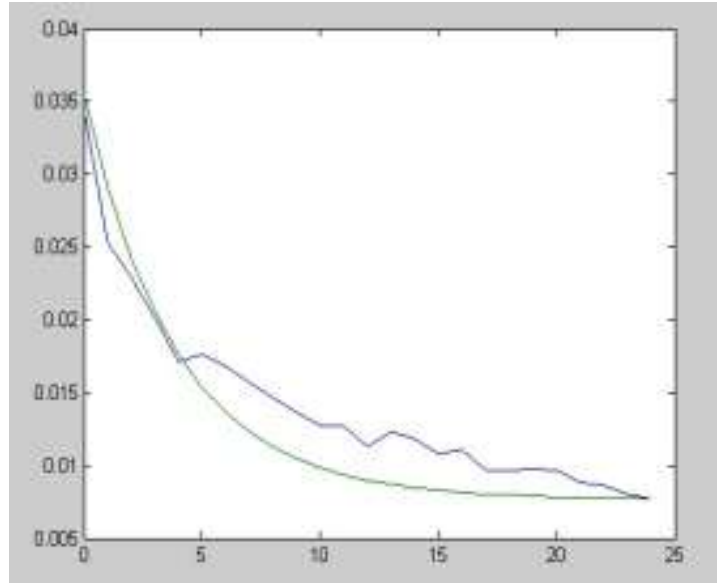

Figure 6. Fitting Results Using Matlab

Then the fitting result is substituted into the original formula and the growth curve of Tianjin Port is shown as fig.7.

The result shows that the maximum throughput for Tianjin Port is 2,500,000 TEU per quarter theoretically or $10,000,000$ TEU per year. However, the present throughput per quarter has already surpassed 1,300,000 TEU. The growth curve shows that the throughput of Tianjin Port has already passed the midpoint. It can be forecast that though the growth rate of Tianjin Port throughput will be maintained at relatively high level, it will decelerate in the future. If its high-speed development trend is to be kept, Tianjin Port needs to make improvements in port reorganization and expansion, the expansion of its economic hinterlands and supporting facilities of harbor operation as well as the boost in its shipment and traffic capacity. It is hoped that through improving external environment, the potentiality of Tianjin Port will be fully tapped.

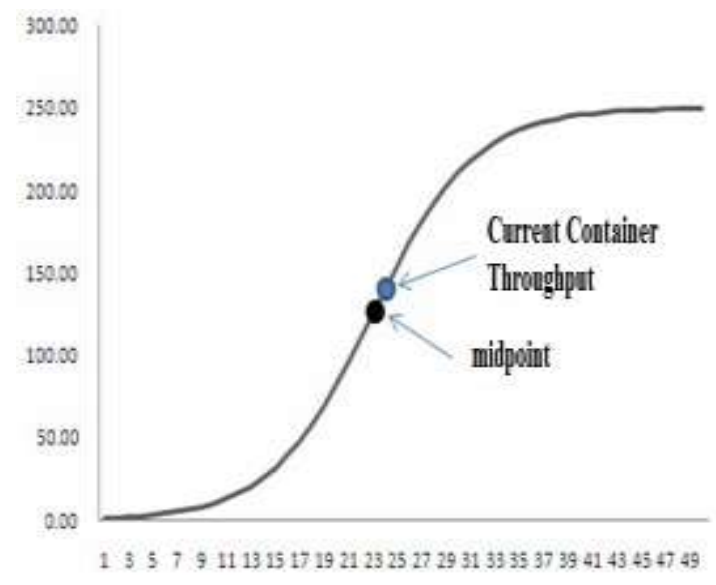

Figure 7. Logistic Growth Curve of Tianjin Port Container Throughput

\section{ACKNOWLEDGEMENT}

The project is supported by Tianjin Municipal Fund of Humanities and Social Science No. 20132127, and the Future Stars Project of Tianjin Foreign Studies University.

\section{REFERENCES}

[1] Yih-ching JUANG, Michael ROE, A Study on Success Factors of Development Strategies for Intermodal Freight Transport Systems. Journal of the Eastern Asia Society for Transportation Studies, 2010, Vol. 8

[2] Genevieve Giuliano, Peter Gordon, Qisheng Pan, JiYoung Park, LanLan Wang. Estimating Freight Flows for Metropolitan AreaHighway Networks Using Secondary Data Sources. Springer Science Business Media, 2007,6(3),39 42

[3] Milan Janic, Modelling the full costs of an intermodal and road freight transport network. ScienceDirect Transportation Research Part D, 2007, 12(4),33 44

[4] Seung-Ju Jeong, Seung-Ju Jeong, James H. Bookbinder, The European freight railway system as a hub-and-spoke network. ScienceDirect Transportation Research Part A : 2007,41(7),523 536

[5] David Hensher and Miguel Andres Figliozzi, Behavioural insights into the Modelling of Freight Transportation and Distribution Systems. The University of Sydney. 2007

[6] Teodor Gabriel Crainic, Michel Gendreau, Jean-Yves Potvin. Intelligent freight-transportation systems: Assessment and the contribution of operations research. ScienceDirect Transportation Research Part C: 2009, 17(5),541 557

[7] Harry K.H. Chow, K.L. Choy, W.B. Lee. A strategic knowledgebased planning system for freight forwarding industry. Expert Systems with Applications: 2007,33(2),936 954

[8] Zhang Shengxian, Ma Fei, et al. Research on the Coal Collecting and Distributing System of Longkou Port. China Water Transport: 2007,2 (2) , 17 18

[9] Liu Yun. Study on Traffic Flow for Container Port Area Based on Principles of Hydrodynamics and Entropy. [D], Qingdao: Ocean University of China, 2008

[10] Deng Chaofeng, Study on Throughput Prediction Model of Main Port in the Bohai Bay Port Cluster: [D], Wuhan: Wuhan University of Technology, 2006

[11] Gao Qin, Ma Junhai, Research on Co-opetition Strategy Between Container Terminals, Journal of Xidian University (Social Sciences Edition), 2009, 3(5):77〜80 